\title{
Topical axitinib is a potent inhibitor of corneal neovascularization
}

Mariola LLedó Riquelme MD, ${ }^{1}$ Ezequiel Campos-Mollo $\mathrm{PhD}^{1}$ and Laura FernándezSánchez $\mathrm{PhD}^{2}$

1. Hospital Virgen de los Lirios; Department of Ophthalmology, Alcoy, Alicante, Spain 2. University of Alicante, Department of Physiology, Genetics and Microbiology, Alicante, Spain

Correspondence: María Dolores Lledó Riquelme, C/ Gonzalo Barrachina nº $12-1^{\circ} \mathrm{A}$ C. P. 03801 Alcoy (Alicante)

Email address: mariola.lledo@hotmail.com

Short running title: Axitinib for corneal neovascularization

Received 22 January 2018; accepted 16 May 2018

Conflict of interest: None

Funding sources: Publication of this article was supported in part by a research grant from the Institute of Health Carlos III (PS09/02407), Madrid, Spain.

\section{ABSTRACT}

Background: To evaluate the effects of topically applied axitinib, a tyrosine kinase inhibitor, in an experimental model of corneal neovascularization (CNV).

Methods: Forty-eight New Zealand rabbits were used. CNV was induced by placing 5 silk sutures in the upper cornea of one eye per rabbit. Rabbits were randomized into four groups (12 rabbits each): $0.9 \%$ saline (control group), $0.02 \mathrm{mg} / \mathrm{ml}$ axitinib, $0.35 \mathrm{mg} / \mathrm{ml}$ axitinib and $0.5 \mathrm{mg} / \mathrm{ml}$ axitinib groups. All treatments were administered three times daily for 14 days. Photographs were taken using a slit lamp on day 7 and 14. The area of neovascularization was measured in $\mathrm{mm} 2$, as the percentage of total corneal area and as the percentage of corneal surface covered by sutures.

Results: On day 14, the CNV area in the control group $(31.50 \pm 7.47 \mathrm{~mm} 2 ; 115.00$

This article has been accepted for publication and undergone full peer review but has not been through the copyediting, typesetting, pagination and proofreading process, which may lead to differences between this version and the Version of Record. Please cite this article as doi: $10.1111 /$ ceo. 13333 
$\pm 22.55 \%$ of the corneal surface covered by sutures) was larger than that in the $0.02 \mathrm{mg} / \mathrm{ml}$ axitinib group (19.20 $\pm 8.92 \mathrm{~mm} 2 ; 73.89 \pm 34.98 \%$ ), the $0.35 \mathrm{mg} / \mathrm{ml}$ axitinib group ( $8.83 \pm 3.92 \mathrm{~mm} 2 ; 31.90 \pm 13.59 \%)$ and the $0.5 \mathrm{mg} / \mathrm{ml}$ axitinib group (5.12 $\pm 3.97 \mathrm{~mm} 2 ; 18.38 \pm 13.65 \%)$. Compared with saline, CNV was inhibited $39.04 \%$ by $0.02 \mathrm{mg} / \mathrm{ml}$ axitinib, $71.96 \%$ by $0.35 \mathrm{mg} / \mathrm{ml}$ axitinib and $84.73 \%$ by $0.5 \mathrm{mg} / \mathrm{ml}$ axitinib.

Conclusion: Topical administration of the three axitinib concentrations inhibited CNV in rabbits, blocking both VEGF and platelet-derived growth factor pathways. Axitinib at $0.5 \mathrm{mg} / \mathrm{ml}$ induced profound inhibition of corneal angiogenesis.

Keywords: Axitinib, Tyrosine kinase inhibitor, Corneal neovascularization, Cornea, angiogenesis 


\section{NTRODUCTION}

Corneal neovascularization (CNV) is a common consequence of several inflammatory, infectious and traumatic corneal diseases. ${ }^{1}$ In addition, neovascularization introduces circulating immune cells, reducing the immune privilege of the cornea and subsequently compromising the survival of corneal transplant grafts. ${ }^{2}$

VEGF is commonly considered the most prominent angiogenic factor. Among members of the VEGF family, VEGF-A is considered the major factor involved in hemangiogenesis, receiving the greatest attention as a mediator of pathologic neovascularization. VEGF-A and its tyrosine kinase receptors (VEGFR-1 and VEGFR2) are involved in many aspects of the angiogenic process: vascular permeability, survival, migration and proliferation of endothelial cells and capillary tube formation. ${ }^{3,4}$ On the other hand, VEGF-C and VEGF-D bind to the VEGFR-3 receptor with a strong capacity to induce lymphangiogenesis. ${ }^{5}$

Vascular endothelial cells produce PDGF-B and surrounding mural cells, such as pericytes and vascular smooth muscle cells, express its receptor (PDGFR- $\beta$ ). PDGF induces the recruitment of pericytes and allows the maturation of neoformed vessels. ${ }^{6}$ Blood vessel maturation can be characterized by a decreased sensitivity to anti-VEGF therapy. Therefore, removal of pericytes from unwanted blood vessels may expected to increase susceptibility of the vessels to regression factors. ${ }^{6,7}$ Thus, a combined inhibition of the signalling pathway of both VEGF and PDGF could be more effective than only inhibition of the VEGF system for the treatment of CNV. ${ }^{6,8}$

Conventional CNV therapy is based on the administration of corticosteroids. The antiangiogenic effect of steroids is thought to result from multiple antiinflammatory properties ${ }^{9}$. However, corticosteroids are not always effective and can induce long-term side effects including the development of cataracts, glaucoma and increased risk of infection. ${ }^{2}$ The most commonly used anti-VEGF for off-label treatment of CNV is bevacizumab, a recombinant monoclonal antibody that directly acts against VEGF-A isoforms. However, experimental and clinical studies have shown that bevacizumab only partially reduces $\mathrm{CNV} .{ }^{8,10-13}$ 
Tyrosine kinase inhibitors (TKIs) are small molecules that can inhibit the cascade of intracellular signal transduction stimulated by one or more tyrosine kinase receptors. ${ }^{14}$ These molecules have been well established as clinically useful drugs for the treatment of cancer.

Axitinib is a potent synthetic molecule that stabilizes the kinase domain in an inactive conformation (TKI type II), blocking VEGF transduction signal. ${ }^{15}$. However, additional effects may occur on other targets including PDGFR.$-{ }^{16}$ To the best of our knowledge, no work has yet to evaluate the antiangiogenic effects of topically administrated axitinib on corneal neovascularization. Thus, the purpose of the present study was to investigate the antiangiogenic capacity of topically administrated axitinib in a rabbit suture-induced CNV model.

\section{METHODS}

\section{Axitinib (AG-013736)}

Axitinib is a potent small TKI derived from indazole (mw $386.47 \mathrm{Da}$ ) that has been demonstrated to be advantageous in a wide variety of tumours including melanomas, colorectal carcinomas, and tumours of the pancreas, thyroid, breast, and lung. ${ }^{17-19}$ At picomolar concentrations, it is a potent and highly selective inhibitor of VEGF tyrosine kinase receptors (VEGFR-1, VEGFR-2 and VEGFR-3). At nanomolar concentrations, it also inhibits the platelet-derived growth factor receptors $a$ and $\beta$ (PDGF- $a$ and- $\beta$ )

Three topical concentrations of axitinib were selected based on the following rationale: a) $\mathbf{0 . 0 2} \mathbf{~} \mathbf{~ g} / \mathbf{~ m l}$ axitinib: an axitinib concentration comparable to previous studies of $5 \mathrm{mg} / \mathrm{ml}$ bevacizumab to obtain comparable results. As a reference, we considered the in vitro results of the inhibition of human umbilical vein endothelial cell (HUVEC) proliferation induced by human VEGF 165 acting on VEGFR-2. Drug concentrations for topical use were obtained from the product of its $\mathrm{IC}_{50} \times$ 222,222 because the used concentration of $5 \mathrm{mg} / \mathrm{ml}$ bevacizumab is approximately 222,222 times its IC $_{50}$; b) $\mathbf{0 . 3 5} \mathbf{~} \mathbf{~ g / ~} \mathbf{~} \mathbf{~ l}$ axitinib: an axitinib concentration comparable to $0.5 \mathrm{mg} / \mathrm{ml}$ sunitinib, as used in our previous studies. ${ }^{8,20}$ This concentration was calculated by considering the molecular weight of the drug to 
employ the same number of moles; and c) $\mathbf{0 . 5} \mathbf{~ m g / ~} \mathbf{~ m l}$ axitinib: an equivalent dose to that used in previous studies of other TKIs, including sunitinib ${ }^{8,20}$ and pazopanib. ${ }^{21,22}$

Axitinib was prepared from the active ingredient provided by LC laboratories (free base axitinib, LC Laboratories, Woburn, MA, USA) and dissolved in saline to the desired concentration.

\section{Experimental model and study groups}

A total of $48 \mathrm{New}$ Zealand rabbits weighing 2.5 to $3 \mathrm{~kg}$ were randomly assigned to 4 groups (12 rabbits per group) corresponding to each of the selected drugs: Group 1 (control group) saline; group 2: axitinib $0.02 \mathrm{mg} / \mathrm{ml}$; group 3: axitinib $0.35 \mathrm{mg} / \mathrm{ml}$; and group 4: axitinib $0.5 \mathrm{mg} / \mathrm{ml}$.

A corneal neovascularization model was induced in the right eye of each rabbit with a triangular pattern based on the placement of five 8/0 interrupted blue virgin silk sutures suture (LorcaMarin SA, Murcia, Spain) at midstromal depth in the upper cornea following a limbal-based triangular pattern ${ }^{23}$ (Figure $1 \mathrm{a}$ ).

Figure 1: a) Suture technique used to induce corneal neovascularization in rabbits;

b) measurement of the stimulus area represented by the surface covered by sutures (SCS) using image processing software. 


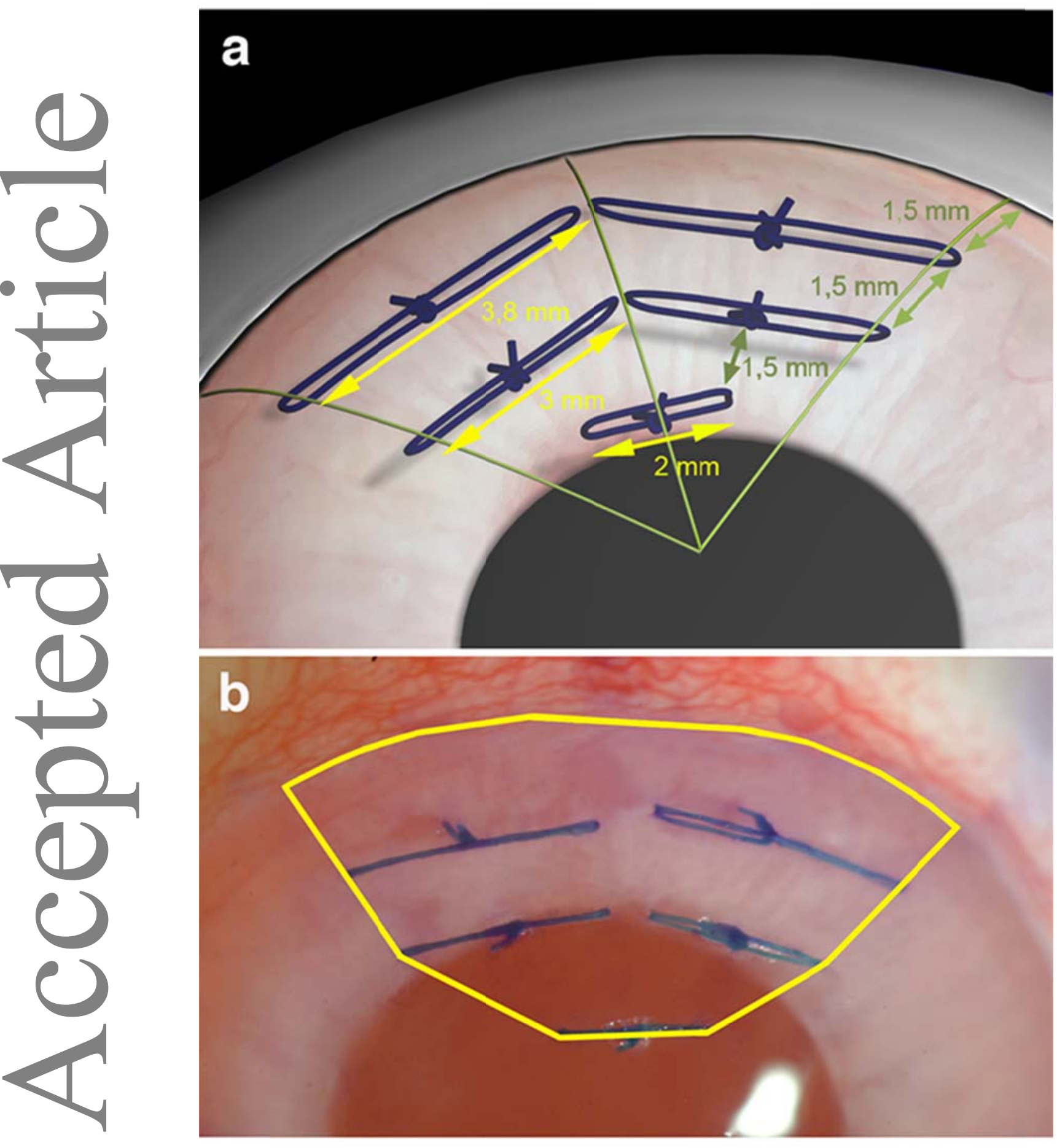

Beginning the following day, 2 drops of the selected agent were topically administered three times a day (every 8 hours) for two weeks. 
Under anaesthesia, slit-lamp photographic control was performed to quantify the angiogenic stimulus surface (surface covered by sutures, SCS) on day 3 and the corneal neovascularization surface (CNVS) on day 14.

The rabbits were sacrificed after two weeks, and the corneas were processed by enzymatic staining to analyse the vascular microdensity. Eight eyes were designated to analyse vascular morphology, and four eyes, for the anatomopathological study.

The measurement and quantification of all experimental procedures were performed by an examiner blinded to all treatment groups. All procedures and experimentation with the animals were performed according to the ARVO (Association for Research in Vision and Ophthalmology) standards for animal handling.

\section{Measurement of the surface covered by sutures (SCS) and quantification of CNV surface (CNVS)}

Two calibrated colour photographs of each cornea were taken to measure the corneal SCS on day 3 of follow-up. The corneal photographs were captured at a magnification of $\times 10$ using a FinePix S2Pro digital camera (Fuji Photo Film Corporation Limited, Tokyo, Japan) attached to a slit-lamp (SL-D7, Topcon Corporation, Tokyo, Japan). Image-Pro Plus V.6.0 software (Media Cybernetics Incorporated, Bethesda, Maryland, USA) designed for image processing and analysis was employed.

On day 14 , rabbit corneas were also evaluated by slit-lamp biomicroscopy to quantify the CNVS. Two colour and one red-free photographs were calibrated using a graduated ruler with a resolution of $0.5 \mathrm{~mm}$. The mean value from all 3 photographs was used.

\section{Vascular microdensity and anatomopathological studies}

Eight eyes from each group were allocated for assessments of vascular morphology and vascular microdensity. The corneas were sectioned to obtain a block of triangular tissue containing the area covered by the sutures and, therefore, 
the CNVS. The blocks of corneal tissue were processed by enzymatic staining using the NADPH diaphorase technique.

As shown in Figure 2, two areas were analysed. Zone one was located between the limbus and the first row of suture points, and zone 2 was located between the first and second rows. Two points were selected for each zone: points were selected $750 \mu \mathrm{m}$ from the limbus in zone one (sections A and B) and $2.250 \mu \mathrm{m}$ from the limbus in zone 2 (sections $C$ and $D$ ) at the centre of each suture.

Figure 2: Schematic of the vascular microdensity study zones.

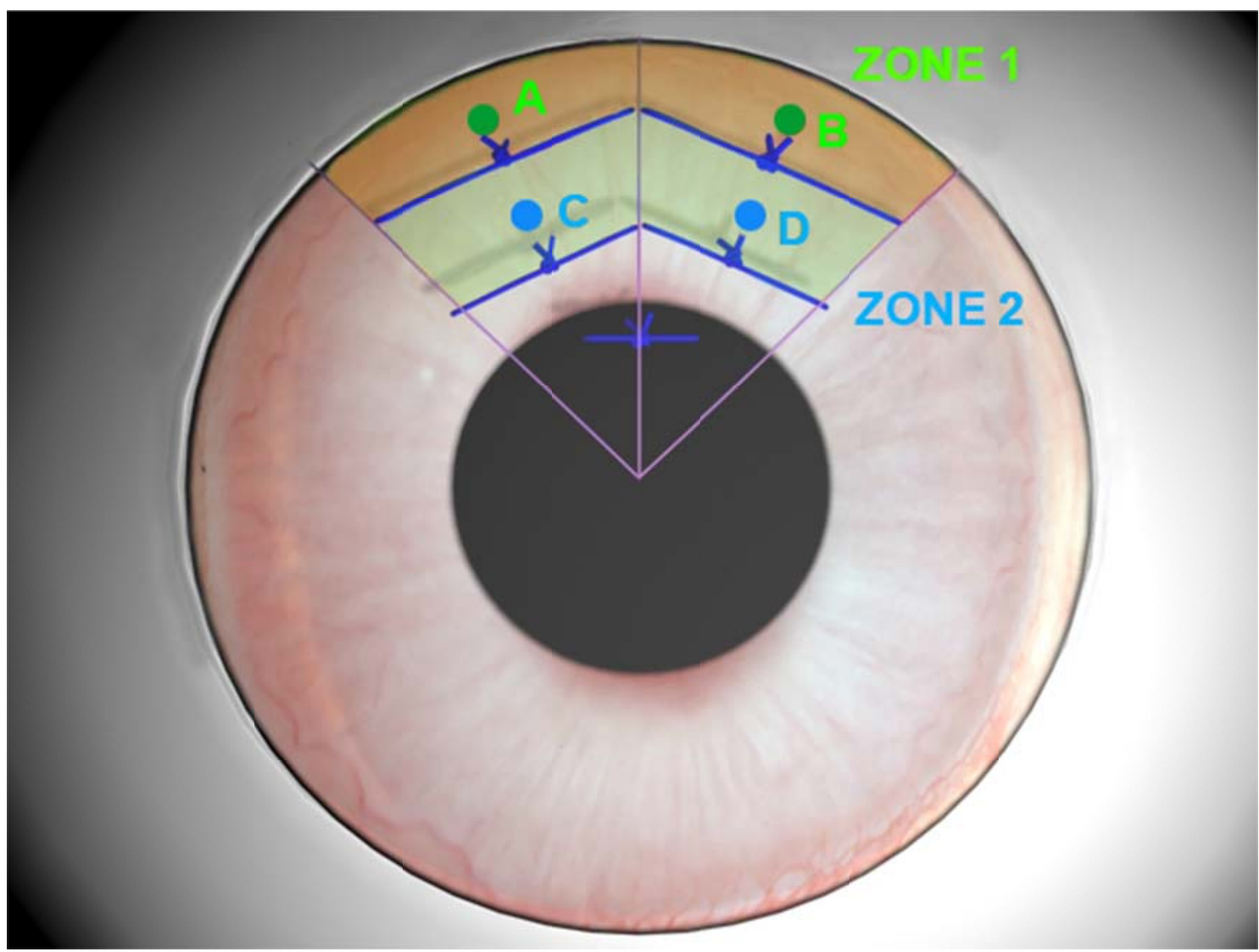

In each zone, the corneal stroma area of both sections was measured and added to obtain the overall stromal area, as shown in Figure 3. All measurements were made using Image-Pro Plus software to calculate the vascular microdensity. (Figure 3). 
Figure 3: The corneal stroma area to be studied was calculated by adding the corneal stroma areas of the 2 sections of each zone. Based on the sum of the stromal areas, the vessels and vascular microdensity were analysed. 

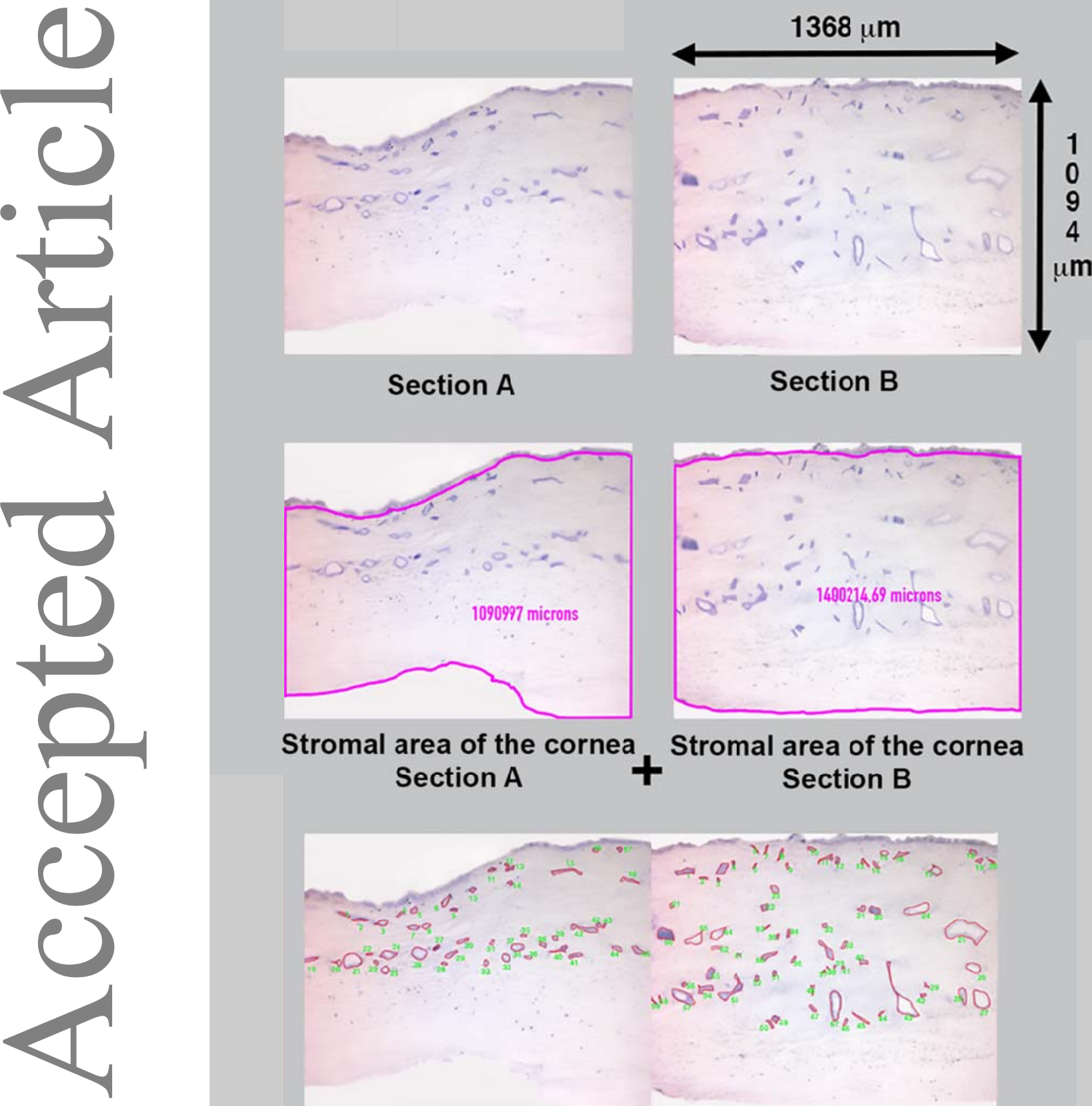

Section A

\section{Section B}
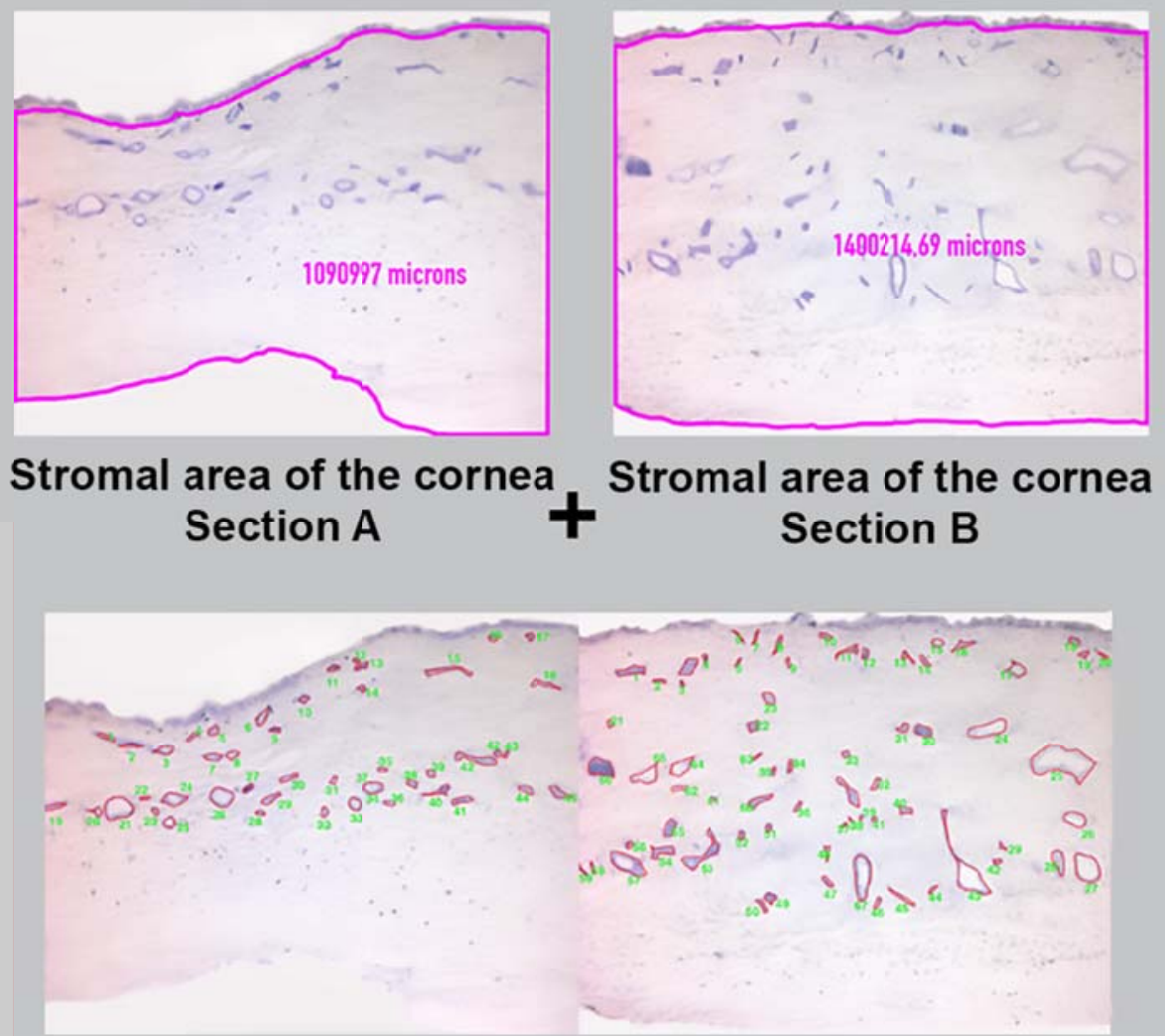

\section{Total stromal area from each Zone}

The diameter of a capillary is approximately 5 to $10 \mu \mathrm{m}$. Therefore, to avoid false positives, structures under $5 \mu \mathrm{m}$ were excluded, as NADPH diaphorase technique can stain the nuclei of some cells that are likely involved in the 
inflammatory response, as well as individual nerve fibres of the sub-basal plexus whose diameters vary between 0.05 and $0.25 \mu \mathrm{m}$.

Four eyes from each group were allocated to the anatomopathological study. These eyes were stained using haematoxylin-eosin to evaluate the structural changes of the sutures, inflammatory infiltration, the distribution of corneal blood vessels in the corneal stroma, etc.

\section{Statistical analysis}

Parametric statistical tests were performed after verifying a normal distribution of the data by the one-sample Kolmogorov-Smirnov procedure. Differences were considered statistically significant when $p$ values were less than 0.05 .

\section{RESULTS}

\section{Corneal neovascularization surface (CNVS)}

CNVS data for each group are shown in Table 1, expressed in terms of square $\mathrm{mm}$ and the percentage of neovascularized area to corneal SCS.

\begin{tabular}{|c|c|c|c|c|c|}
\hline & Group 1 & Group 2 & Group 3 & Group 4 & 1-Way \\
\hline & Saline & $\begin{array}{c}\text { Axitinib } \\
0.02 \\
\mathrm{mg} / \mathrm{ml}\end{array}$ & $\begin{array}{c}\text { Axitinib } \\
0.35 \\
\mathrm{mg} / \mathrm{ml}\end{array}$ & $\begin{array}{c}\text { Axitinib } \\
0.5 \\
\mathrm{mg} / \mathrm{ml}\end{array}$ & ANOVA \\
\hline Square $\mathrm{mm}$ & $\begin{array}{c}31.50 \pm \\
7.47\end{array}$ & $\begin{array}{c}19.20 \pm \\
8.92\end{array}$ & $\begin{array}{c}8.83 \pm \\
3.92\end{array}$ & $\begin{array}{c}5.12 \pm \\
3.97\end{array}$ & $\begin{array}{l}\mathrm{P}< \\
.001\end{array}$ \\
\hline $\begin{array}{l}\text { Percentage of } \\
\text { neovascularized area } \\
\text { to corneal area } \\
\text { covered by sutures }\end{array}$ & $\begin{array}{c}115.00 \pm \\
22.55\end{array}$ & $\begin{array}{c}73.89 \pm \\
34.98\end{array}$ & $\begin{array}{c}31.90 \pm \\
13.59\end{array}$ & $\begin{array}{c}18.38 \pm \\
13.75\end{array}$ & $\begin{array}{l}\mathrm{P}< \\
.001\end{array}$ \\
\hline Inhibition rate & $0 \%$ & $39.04 \%$ & $71.96 \%$ & $83.74 \%$ & \\
\hline
\end{tabular}


CNVSs measured on the calibrated photographs are shown in Figure 4.

Figure 4: Colour and red-free photographs of rabbit corneas showing the corneal neovascularization area (yellow line) after 14 days of treatment in all experimental groups.
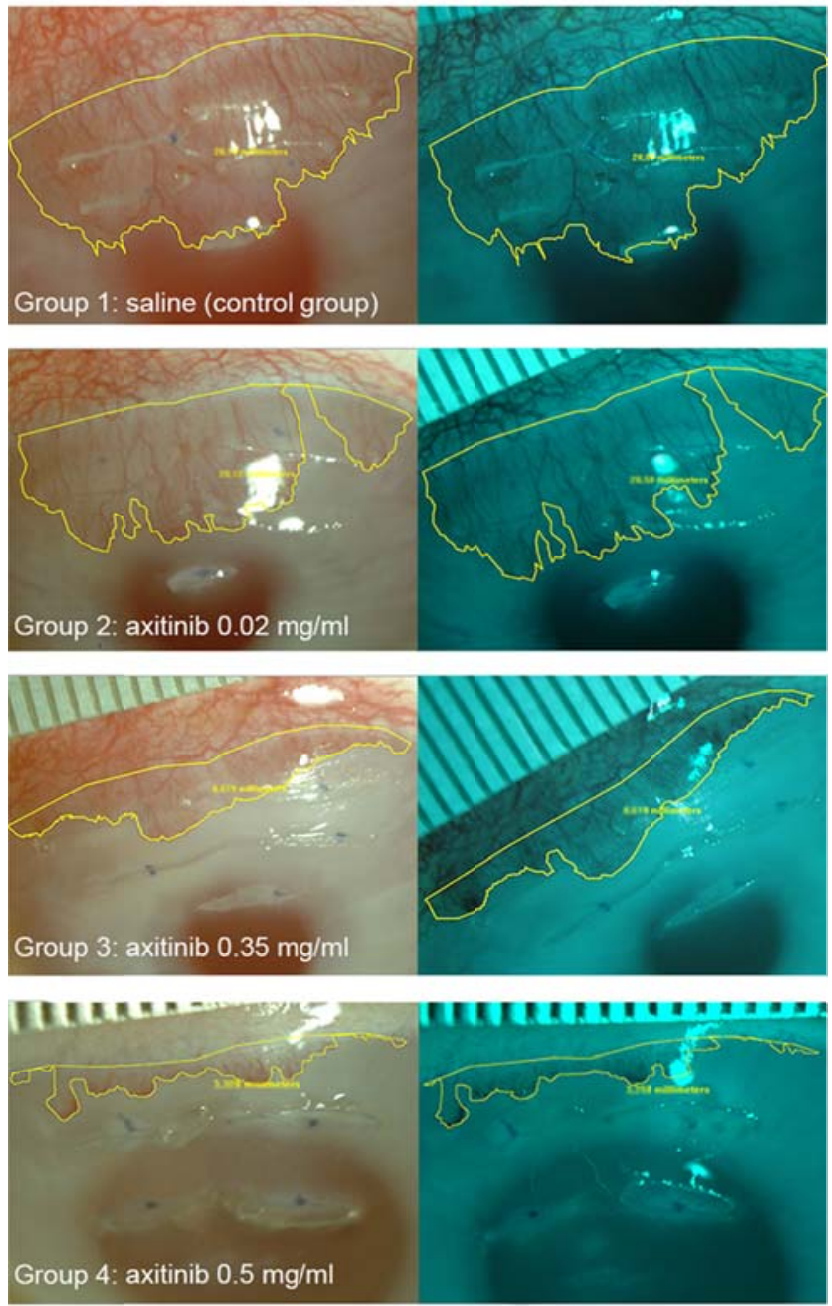

On day 14, group 1 (saline) presented a CNVS of $31.50 \pm 7.47 \mathrm{~mm}^{2}$, constituting $115.00 \pm 22.55 \%$ of the SCS. This result demonstrated that the area of the corneal surface covered with neovascular vessels increased with time in group 1 , and fourteen days were sufficient for the new blood vessels to cover all of the 
stimulating area (SCS). In group 2 (axitinib $0.02 \mathrm{mg} / \mathrm{ml}$ ), the CNVS was $19.20 \pm$ $8.92 \mathrm{~mm}^{2}$, corresponding to $73.89 \pm 34.98 \%$ of the SCS, and group 3 showed a CNVS of $8.83 \pm 3.92 \mathrm{~mm}^{2}$, representing $31.90 \pm 13.59 \%$ of the SCS. In group 4 , the CNVS also increased during the follow-up period to $5.12 \pm 3.97 \mathrm{~mm}^{2}$; however, only $18.38 \%$ of the stimulus area was covered by blood vessels on day 14 (Figure 5 ).

Figure 5: Corneal neovascularization surfaces by slit-lamp biomicroscopy 14 days after surgery (mean $\pm \mathrm{SD}$ ) in terms of the percentage of the corneal surface covered by sutures (SCS).

\section{Corneal Neovascularization Surface 14 days after surgery}

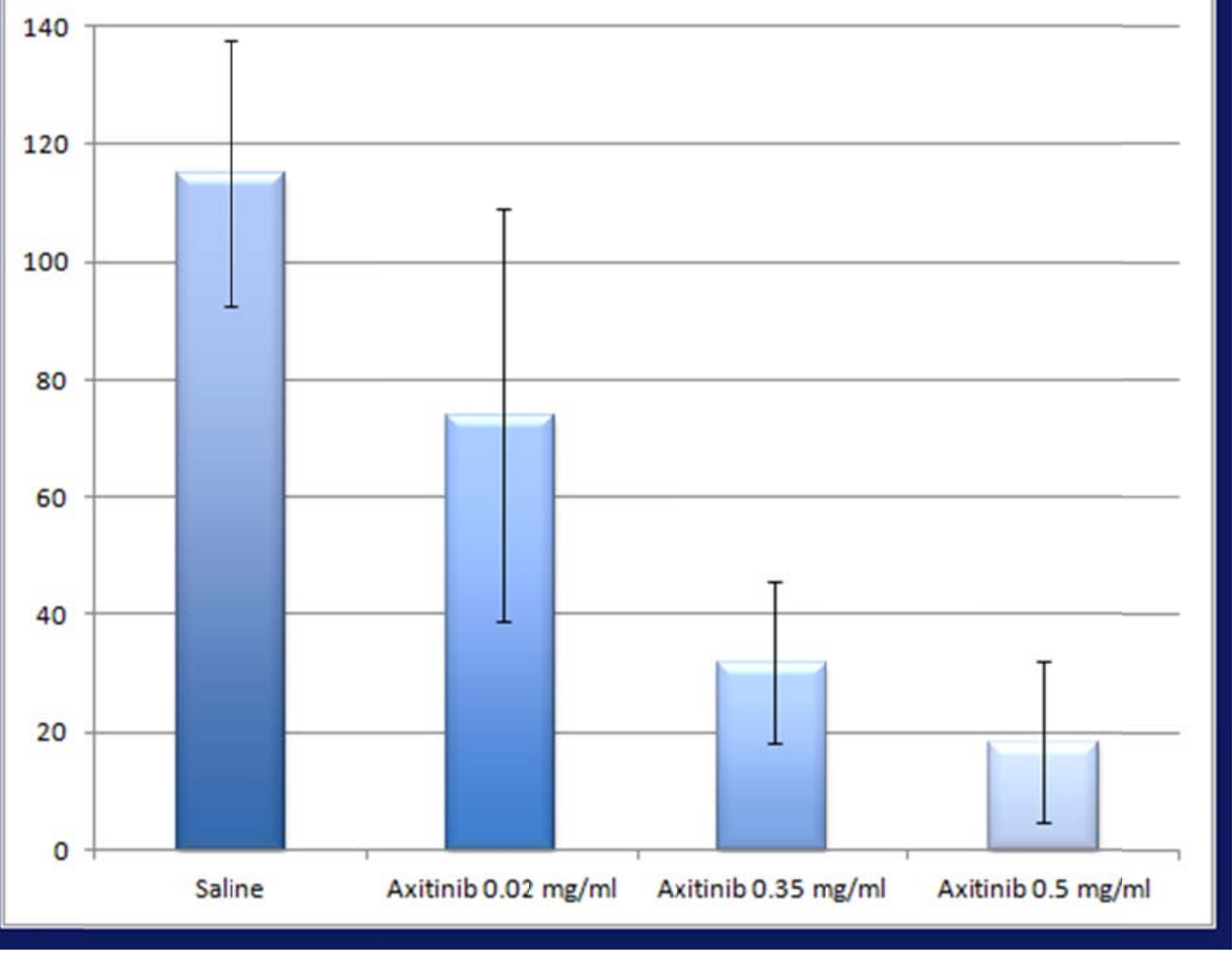

At day 14 , the CNVS measured in $\mathrm{mm}^{2}$ in group 1 was higher than the CNVS in groups 2 (one-way ANOVA, $p=0.009), 3(p<0.01)$ and $4(p<0.001)$. The CNVS in group 2 was also significantly higher than the CNVS in group $3(p=0.013)$ and 
group $4(p=0.01)$. The CNVS in group 3 was higher than that in group 4 , but the difference was not statistically significant $(p=0.172)$. At day 14 , CNV was inhibited $39.04 \%$ by axitinib $0.02 \mathrm{mg} / \mathrm{ml}, 71.96 \%$ by axitinib $0.35 \mathrm{mg} / \mathrm{ml}$ and $83.74 \%$ by axitinib $0.5 \mathrm{mg} / \mathrm{ml}$ compared to CNV in the control group.

\section{Vascular morphology}

Before the section of the corneal samples, microscopy of corneal tissue stained with NADPH diaphorase showed that the emerging pericorneal arteries in group 1 (saline) were represented by branched projections oriented towards the sutures (angiogenic stimulus). As the vascular tree branched out, the uniform gauge of the arteries diminished towards the distal region, forming arterioles and capillaries. In the most distal areas of this vascular plexus of small anastomosing channels were the immature vascular buds of the neovascularization front. The venous vessels from the venules were located in somewhat deeper planes, presenting a greater calibre and softer staining with respect to the arteries. The veins followed a more irregular and sinuous path into the pericorneal veins (Figure 6 a).

In the axitinib-treated groups, the response was in many cases limited to arborescent structures consisting of one or more branched vascular axes. The ramifications emitted by each vascular axis did not present a clear orientation towards the angiogenic stimulus, as in the control group. At the distal ends, the vessels exhibited characteristics of capillaries, with more anastomoses and small vascular sprouts (Figure $6 \mathrm{~b}$ and $\mathrm{c}$ ).

Figure 6: Microscopic photograph of the corneal neovascularization surface stained with NADPH diaphorase in an eye treated with saline. Arterial vessels exhibited darker staining, uniform gauge and straight pathways with some ramifications for angiogenic stimulation. Venous vessels were generally located in deeper planes with soft staining and greater sinuosity. 

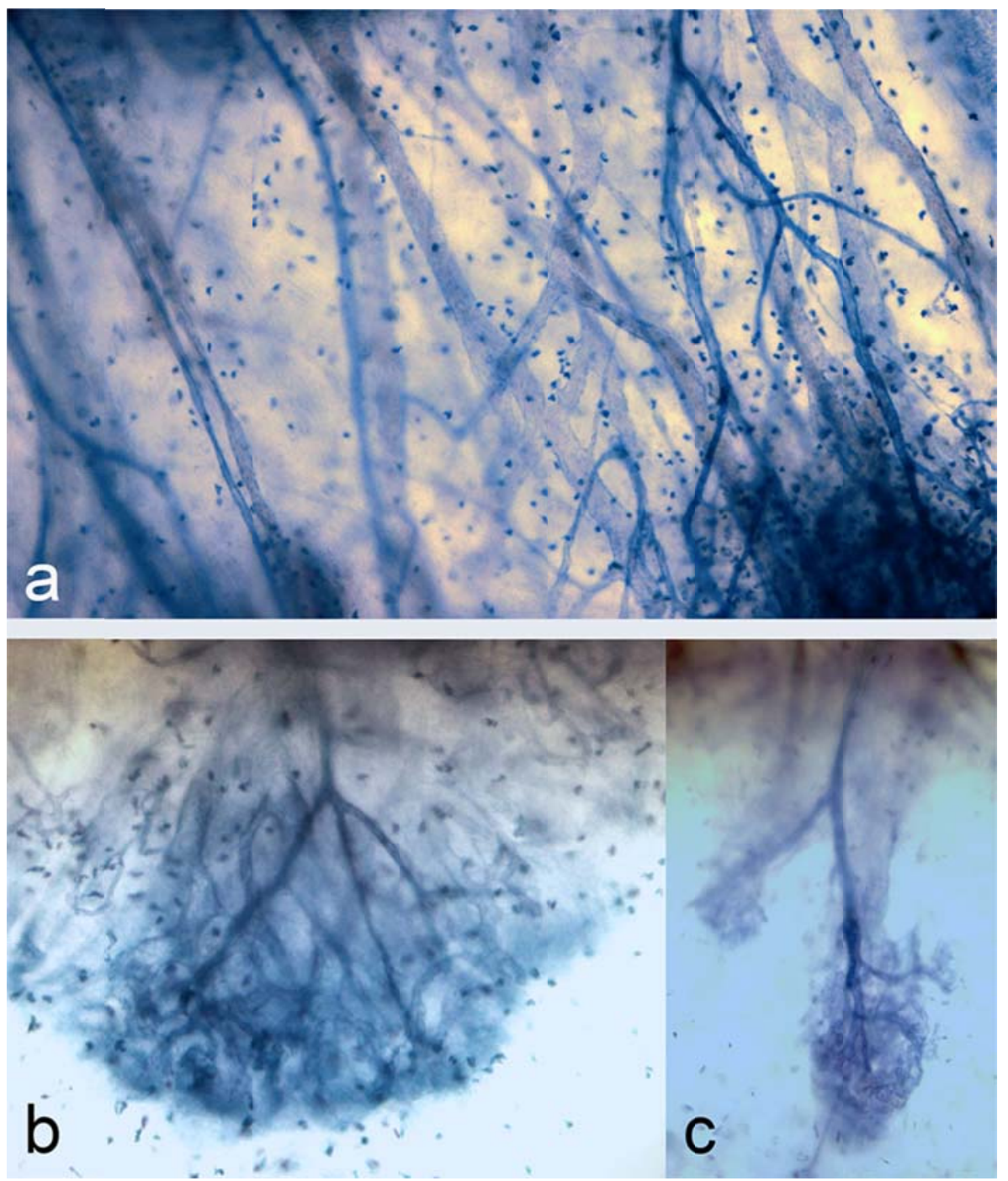

CNVS illustrations of the blood vessels of each group drawn using a camera lucida are shown in Figure 7.

Figure 7: Corneal neovascularization surface illustrations. The blood vessels of each sample were drawn on DIN-A3 paper using a camera lucida included in an optical microscope (Leica Microsystems Limited Heerbrugg, Switzerland). 


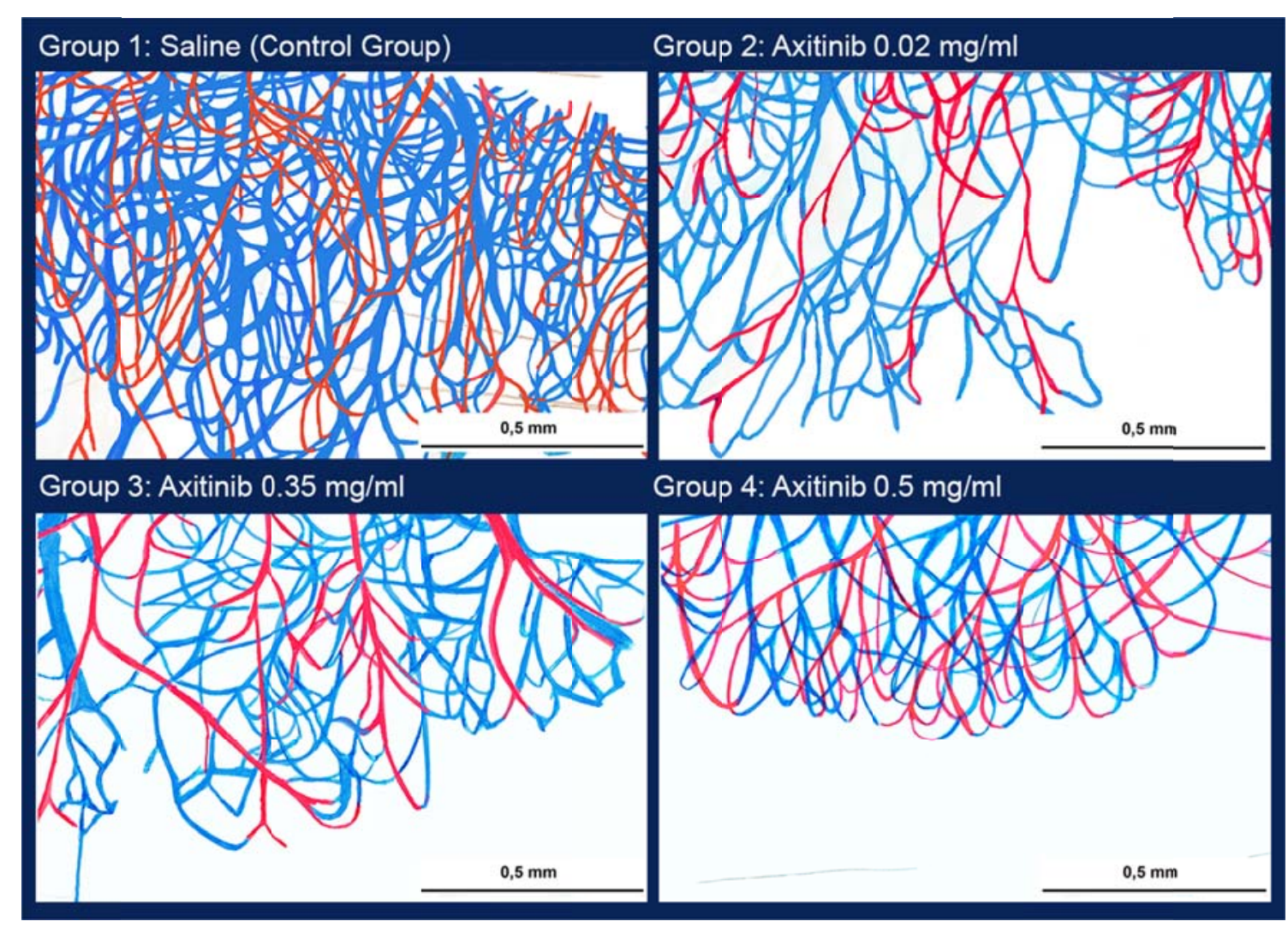

Microvascular density: number of vessels $/ \mathbf{m m}^{2}$ and percentage of vascular area

The number of vessels per $\mathrm{mm}^{2}$ of sectioned corneal stroma represents the microvascular density. Comparing the values of the different groups, rabbits in the control group had a greater number of vessels $/ \mathrm{mm}^{2}$ than rabbits treated with axitinib in both zone $1(p<0.016)$ and zone $2(p<0.019)$. However, when comparing the means between the different groups treated with different concentrations of axitinib, no significant differences were observed ( $p>0.99$ in zone $1, p>0.08$ in zone 2). Therefore, axitinib reduces the number of vessels with respect to the saline treatment (Figure 8).

Figure 8: Corneal sections stained with NADPH diaphorase (100x) in zone 1 and zone 2 of each group. 


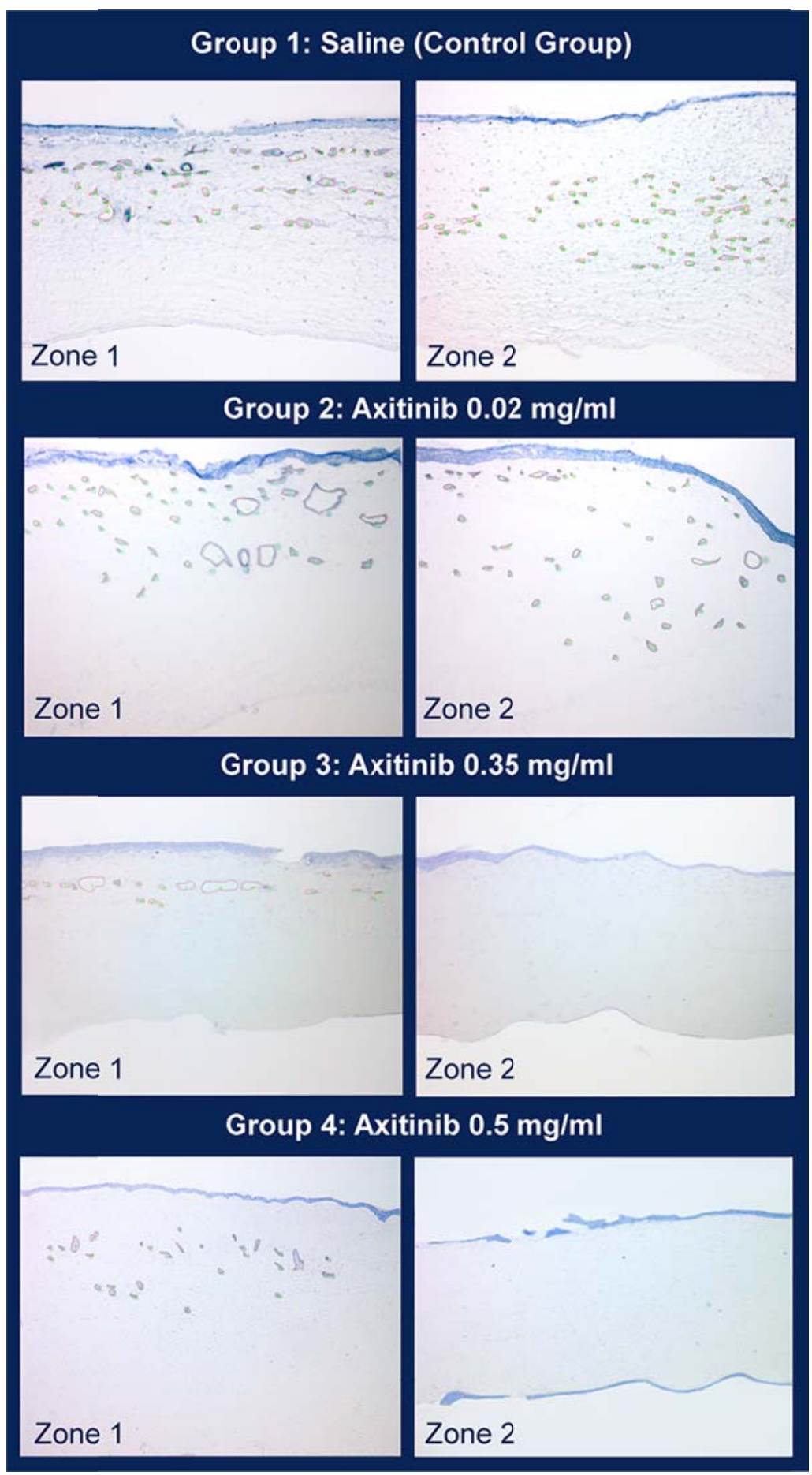

The percentage of vascular area with respect to the sectioned corneal stroma area was calculated according to the following formula: (sum of the section of vessels/stromal area) $\times 100$. The percentage of vascular area was higher in rabbits of the control group than in rabbits treated with axitinib $(p<0.001$ in zone 1 and $p$ $<0.03$ in zone 2). Comparing the three groups treated with axitinib, there were 
significant differences only between group 2 (axitinib $0.02 \mathrm{mg} / \mathrm{ml}$ ) and group 4 (0.5 $\mathrm{mg} / \mathrm{ml})$ in zone $2(\mathrm{p}=0.02)$.

Interestingly, the percentage of vascular area did not exceed $5 \%$ with respect to the sectioned corneal stroma area in any rabbit of any group.

Figure 9 shows the average vessels $/ \mathrm{mm}^{2}$ and percentage of vascular area in zone 1 and zone 2.

Figure 9: Variation between zone 1 (close to the limbus) and zone 2 (distal to the limbus) of the mean area of cut vessels, the number of vessels $/ \mathrm{mm}^{2}$ of stroma and the vascular microdensity in terms of stromal area percentage occupied by vessels. 


\section{Vascular microdensity}
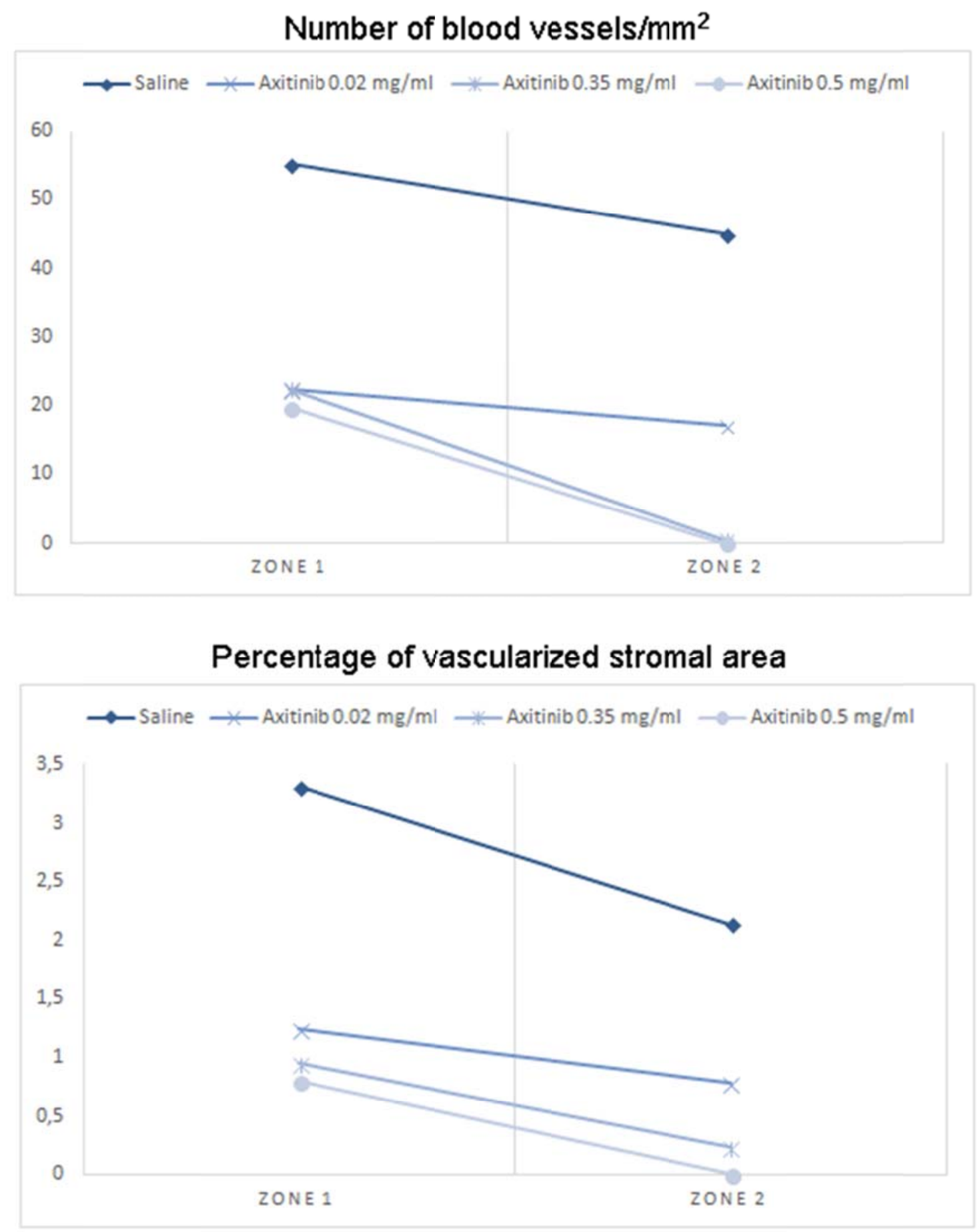

Regarding the comparison of the vascular microdensity between zones 1 and 2 for each group, significant differences were observed in groups 3 and 4 (higher concentrations of axitinib) between zone 1 and 2 . Therefore, we can conclude that, at these concentrations, axitinib inhibited angiogenesis more effectively, inducing a 
downward gradient in the vascular response with greater distances of the stimulus from the limbus.

\section{Anatomopathological study}

Granulomatous inflammation, in which lymphocytes and macrophages were predominant, was observed in the control group. Granulomatous inflammation occurred when macrophages accumulated substances that could not be digested (virgin silk) and transformed into epithelioid cells, constituting granulomas. Epithelioid cells contain an oval nucleus and a large central nucleolus and are organized to form cell masses with minimal space between cells (Figure $10 \mathrm{a}$ ).

Eyes treated with axitinib exhibited a reduced inflammatory reaction, fewer changes in the structure of the stroma in corneal sections with less tissue oedema and fewer blood vessels. In the proximal sutures, the inflammatory reaction manifested itself as smaller-sized and more delimited granulomas. However, at the distal sites, there was a minimal inflammatory reaction characterized by the absence of blood vessels (Figure $10 \mathrm{~b}$ ).

Figure 10: Histological section of rabbit cornea 14 days after surgery. (H \& E X 100): a) Intense inflammatory response in the control group (saline); b) minimal inflammatory reaction at a proximal point of a rabbit cornea treated with axitinib. A small granuloma was well delimited around the sutures. 


\section{Ocular side effects}

The rabbits' eyes did not show signs of conjunctival hyperaemia, corneal ulcers, or iris or lens abnormalities in any of the groups during the study follow-up. In some rabbits of each group, a slight cellular reaction in the anterior chamber (510 cells $/ 1 \times 3 \mathrm{~mm}$ of beam) associated with the surgical procedure occurred, which was resolved in the following days without consequences. Examination of the fundus of the eye was also normal in all groups.

\section{DISCUSSION}

The activity of axitinib is related to the structure of the molecule and the spectrum of inhibition of the kinase. At low concentrations, axitinib appears to be considerably selective for VEGF receptors (VEGFR-1, VEGFR-2 and VEGFR-3). The effects of axitinib result from its binding to the kinase domain of VEGF receptors, stabilizing it in an inactive conformation and, consequently, inhibiting VEGF transduction signal. ${ }^{19}$

Selective VEGF-A blockade, as with monoclonal antibodies, neutralizes the signal initiated by the growth factor. However, there is a range of VEGF subtypes, all of which play a role in signalling the three kinds of VEGF receptors. Because of the central role of VEGFR kinase activity, a small molecule such as axitinib that blocks VEGFR-1, -2 and -3 could provide a complete approach for blocking VEGF signalling, which would include inhibition of hemangiogenesis and lymphangiogenesis.

PDGF-B signalling, through PDGFR- $\beta$ receptors, regulates the recruitment of mural cells into the growing vascular endothelial tube. Mural cells (pericytes and smooth muscle cells) are necessary for normal vessel function and stability. Endothelial vascular sprouts secrete PDGF-B, and by binding to PDGFR- $\beta$ receptors expressed by pericytes, PDGF-B facilitates the proliferation, differentiation and migration of the same pericytes to stabilize new blood vessels. ${ }^{24}$

In 2010, we published the results of an experimental rabbit cornea study comparing sunitinib (anti-VEGF and anti-PDGF) with bevacizumab (monoclonal antiVEGF antibody). We demonstrated that sunitinib topically inhibits CNV by $82.3 \%$ and that topical administration of sunitinib was 3 times more effective than topical 
bevacizumab after 14 days of treatment. ${ }^{8}$ The findings suggested that simultaneous blockade of the VEGF and PDGF systems is more effective in inhibiting CNV than only blockade of the VEGF system. ${ }^{8}$ This fact is of great relevance, since without the support of pericytes and VEGF signalling, apoptosis of the endothelial cell occurs. ${ }^{25-28}$ In a murine model of laser-induced choroidal neovascularization, Kang et al demonstrated that oral administration of axitinib at $5 \mathrm{mg} / \mathrm{kg}$ results in regression of established neovascularization ${ }^{29}$. Consistent with these findings, Giddabasappa et al showed continuous administration of axitinib at a lower dose $(0.875 \mathrm{mg} /$ day $)$ for 7 days significantly inhibited vascular leakage and neovascularization in a rat model of laser-induced choroidal neovascularization. ${ }^{30}$ This ability of axitinib may be a consequence of its activity as a multiple receptor tyrosine kinase inhibitor. Therefore, axitinib, which targets several angiogenic growth factor pathways, including VEGF receptor 2 and PDGF receptor pathways, may be a potent promoter of established choroidal neovascularization regression. ${ }^{29,30}$

To our knowledge, it is the first study to show the antiangiogenic activity of topical axitinib in a model of ocular neovascularization in rabbits. After 14 days of topical treatment with axitinib at different concentrations (groups 2, 3 and 4), significant inhibition of CNVS was observed compared with the control group (group 1 , saline). Axitinib at $0.02 \mathrm{mg} / \mathrm{ml}$ (group 2) inhibited the CNVS by $39.04 \%$, and axitinib at $0.35 \mathrm{mg} / \mathrm{ml}$ (group 3) caused significant and intense inhibition by $71.96 \%$ of the CNVS. The inhibitory response induced by $0.5 \mathrm{mg} / \mathrm{ml}$ axitinib (group 4) was greater, inhibiting neovascularization by $83.74 \%$ with respect to the control group, although no significant differences in inhibition were found between groups 3 and 4 . However, $0.35 \mathrm{mg} / \mathrm{ml}$ axitinib (group 3) and $0.5 \mathrm{mg} / \mathrm{ml}$ axitinib (group 4) were significantly more effective than group $2(0.02 \mathrm{mg} / \mathrm{ml})$ in terms of inhibition of CNVS.

Comparing the results of this study with those obtained in previous trials of sunitinib using the same methodology, $0.35 \mathrm{mg} / \mathrm{ml}$ axitinib and $0.5 \mathrm{mg} / \mathrm{ml}$ axitinib did not induce significant differences in the inhibition of CNVS compared with 0.5 $\mathrm{mg} / \mathrm{ml}$ sunitinib (data not shown). ${ }^{8,20}$ 
It is unclear whether other inhibitory activities of axitinib contribute to its high level of efficacy, although there is some evidence that a simultaneous blockade of PDGF and VEGF-A could be superior to blockade of either alone. In this regard, agents that inhibit multiple angiogenic pathways would be more desirable for improving therapeutic approaches.

In a pathological clinical study in corneal buttons, Cursiefen and coauthors observed that more than $80 \%$ of vessels were covered by pericytes at two weeks after the onset of CNV. ${ }^{31}$ Therefore, combined treatment against endothelial cells and pericytes is necessary to enhance treatment against new blood vessels in an advanced stage of maturation. Pericytes, recruited by the vessels through the action of PDGF, join with the vessel during formation, thus stabilizing it. In this state, endothelial cells become less dependent on VEGF. In addition to the paracrine process, cell-cell contact enhances the survival of vascular endothelial cells. ${ }^{32,33}$ Thus, in an advanced stage of maturation, the vessels are restrictive towards antiVEGF therapy. Attenuation of pericytes caused by PDGF blockade may potentiate the antiangiogenic effect of VEGF receptor inhibitors. ${ }^{34}$ Therefore, more attention should be paid to pericytes and their interactions with endothelial cells to better understand the full potential of antiangiogenic therapy.

In relation to the vascular microdensity, a reduction in the number of vessels and in the percentage of the vascular area with respect to the stroma was observed in the groups treated with axitinib compared to the control group. Among the different concentrations of axitinib, a significant difference was only found between the concentrations of $0.02 \mathrm{mg} / \mathrm{ml}$ axitinib and $0.5 \mathrm{mg} / \mathrm{ml}$ axitinib, with $0.02 \mathrm{mg} / \mathrm{ml}$ axitinib inducing a significantly lower effect.

According to the morphological findings of the vascular tree in the groups treated with axitinib (groups 2-4), the vascular axes consisted of a small-calibre central artery with short branches without a definite orientation, suggest that the molecular and biological processes associated with the VEGF and/or PDGF system could be relevant in the remodelling of neoformed vessels.

Compared with the control group, histological corneal sections of the axitinib groups generally showed lower inflammation with delimited granulomas around the proximal sutures with a more homogeneous and localized distribution of 
lymphoplasmacytic infiltrate, epithelial cells, and macrophages. In the distal sutures of the high-concentration axitinib groups, almost no inflammatory reaction was observed. These characteristics of the immune response could be explained by potent inhibition of blood and lymphatic vessels, allowing access of inflammatory cells to the sutures only by diffusion through the stroma from preexisting limbic vessels and marginal blood vessels. In fact, TKIs, by blocking VEGF receptors, reduce the recruitment of lymphatic precursor cells and antigen-presenting cells (APCs) and suppress the proliferation of vascular endothelial cells. ${ }^{35}$

The safety of topical axitinib for the treatment of CNV was also determined in this study by evaluating ocular and systemic adverse effects. At the different doses studied topical axitinib was well tolerated after 14 days of treatment, and no adverse effects were observed on ocular structures.

The adverse effects profile of axitinib that occurs with continuous systemic administration appears to be comparable with the adverse effect profile that occurs for administration of systemic anti-VEGF medications. The most common of the adverse effects produced by systemic axitinib is fatigue caused by hypothyroidism. ${ }^{18}$ Other related effects are hypertension, anorexia, hoarseness and nausea. ${ }^{36}$ However, adverse effects are generally well managed with dose modification and supportive treatment. ${ }^{17,18,36}$ In treatments to suppress VEGF for neovascular diseases of the eye, the following factors must be considered. In the cornea, VEGF appears to have a neurotrophic effect. Thus, caution should also be taken when applying anti-VEGF treatments in the presence of epithelial defects or in situations where healing of a corneal wound occurs. ${ }^{37}$ On the other hand, in a murine model with a PDGF-B deficiency, the presence of focal vascular retinopathy accompanied by a loss of mural cells (pericytes) of the vessels has been described, and such mice develop a pathology similar to diabetic retinopathy. ${ }^{25,38}$

In previous experimental studies of sunitinib in rabbits, yellowish staining was observed in the iris of the eyes of all rabbits, which disappeared within a few days after discontinuation of treatment. This staining was caused by deposition of sunitinib on the surface of the iris because the agent in suspension has a goldenyellow colour. The deposition of sunitinib on the surface of the iris was largely relevant, because the yellow colour functioned as a tracer indicating that the 
molecule was able to reach the anterior chamber after topical application. This finding could be of great clinical utility for the treatment of intraocular neovascular diseases. ${ }^{8,39}$

However, it is true that, in clinical practice, an undesired side effects must be considered, especially for prolonged or chronic treatments. In our study, we did not observe any adverse side effects with axitinib treatment because it is white, and after dilution with saline serum, becomes colourless.

In summary, a novel, topically administered, tyrosine kinase receptor inhibitor, axitinib, significantly and extensively inhibited corneal neovascularization in rabbit eyes. The high capacity of axitinib to block neovascularization in the cornea could be a consequence of its multitargeting activity, inhibiting both VEGF and PDGF. In addition, by blocking VEGFR-3, axitinib could inhibit corneal lymphangiogenesis and was able to promote the survival of corneal grafts after corneal transplant.

Axitinib, at the doses and duration used in the study, is safe and well tolerated. However, further studies are needed to define the possible side effects and toxicity of this drug when used in the eye for an extended period of time. Additional studies are needed to determine its mechanisms of action, optimal doses, and side effects. In this context, it is mandatory to carry out randomized controlled clinical trials to establish the effectiveness and safety of the treatment regimens of axitinib for future applications as a therapeutic alternative for treating ocular neovascular pathology.

\section{Acknowledgements}

We thank JJ Perez Santonja for providing insight and expertise in the early stages of the research.

We thank our colleague JJ Alio for assistance and comments that greatly improved the manuscript.

We would also like to express our gratitude to Nicolas Cuenca for his comments and experience in the histological study. 


\section{REFERENCES}

1. Cursiefen C, Kuchle M, Naumann GO. Angiogenesis in corneal diseases: histopathologic evaluation of 254 human corneal buttons with neovascularization. Cornea 1998; 17: 611-3.

2. Maddula S, Davis DK, Maddula S, Burrow MK, Ambati BK. Horizons in therapy for corneal angiogenesis. Ophthalmology 2011; 118: 591-9.

3. Chang JH, Gabison EE, Kato T, Azar DT. Corneal neovascularization. Curr Opin Ophthalmol 2001; 12: 242-9.

4. Azar DT. Corneal angiogenic privilege: angiogenic and antiangiogenic factors in corneal avascularity, vasculogenesis, and wound healing (an American Ophthalmological Society thesis). Trans Am Ophthalmol Soc 2006; 104: 264302.

5. Shibuya M. Vascular endothelial growth factor-dependent and -independent regulation of angiogenesis. BMB Rep 2008; 41: 278-86.

6. Jo N, Mailhos C, Ju M, Cheung E, Bradley J, Nishijima K, Robinson GS, Adamis AP, Shima DT. Inhibition of platelet-derived growth factor $B$ signaling enhances the efficacy of anti-vascular endothelial growth factor therapy in multiple models of ocular neovascularization. The American journal of pathology 2006; 168: 2036-53.

7. Motiejunaite R, Kazlauskas A. Pericytes and ocular diseases. Experimental eye research 2008; 86: 171-7.

8. Perez-Santonja JJ, Campos-Mollo E, Lledo-Riquelme M, Javaloy J, Alio JL. Inhibition of corneal neovascularization by topical bevacizumab (Anti-VEGF) and Sunitinib (Anti-VEGF and Anti-PDGF) in an animal model. $A m \mathrm{~J}$ Ophthalmo/ 2010; 150: 519-28 e1.

9. Gupta D, Illingworth C. Treatments for corneal neovascularization: a review. Cornea 2011; 30: 927-38.

10. Bock F, Onderka J, Dietrich T, Bachmann B, Kruse FE, Paschke M, Zahn G, Cursiefen C. Bevacizumab as a potent inhibitor of inflammatory corneal angiogenesis and lymphangiogenesis. Investigative ophthalmology \& visual science 2007; 48: 2545-52. 
11. Kim TI, Kim SW, Kim S, Kim T, Kim EK. Inhibition of experimental corneal neovascularization by using subconjunctival injection of bevacizumab (Avastin). Cornea 2008; 27: 349-52.

12. Dastjerdi MH, Al-Arfaj KM, Nallasamy N, Hamrah P, Jurkunas UV, Pineda R, 2nd, Pavan-Langston D, Dana R. Topical bevacizumab in the treatment of corneal neovascularization: results of a prospective, open-label, noncomparative study. Arch Ophthalmo/ 2009; 127: 381-9.

13. Bahar I, Kaiserman I, McAllum P, Rootman D, Slomovic A. Subconjunctival bevacizumab injection for corneal neovascularization. Cornea 2008; 27: 1427.

14. Smyth LA, Collins I. Measuring and interpreting the selectivity of protein kinase inhibitors. J Chem Bio/2009; 2: 131-51.

15. Gross-Goupil M, Francois L, Quivy A, Ravaud A. Axitinib: a review of its safety and efficacy in the treatment of adults with advanced renal cell carcinoma. Clin Med Insights Oncol 2013; 7: 269-77.

16. Kernt M, Thiele S, Liegl RG, Kernt B, Eibl K, Haritoglou C, Ulbig MW, Kampik A. Axitinib modulates hypoxia-induced blood-retina barrier permeability and expression of growth factors. Growth Factors 2012; 30: 49-61.

17. Cohen EE, Rosen LS, Vokes EE, Kies MS, Forastiere AA, Worden FP, Kane MA, Sherman E, Kim S, Bycott P, Tortorici M, Shalinsky DR, Liau KF, Cohen RB. Axitinib is an active treatment for all histologic subtypes of advanced thyroid cancer: results from a phase II study. J Clin Onco/2008; 26: 4708-13.

18. Schiller JH, Larson T, Ou SH, Limentani S, Sandler A, Vokes E, Kim S, Liau K, Bycott $P$, Olszanski AJ, von Pawel J. Efficacy and safety of axitinib in patients with advanced non-small-cell lung cancer: results from a phase II study. $J$ Clin Oncol 2009; 27: 3836-41.

19. Kelly RJ, Rixe O. Axitinib (AG-013736). Recent Results Cancer Res 2010; 184: 33-44.

20. Perez-Santonja JJ, Campos-Mollo E, Lledo-Riquelme M, Fernandez-Sanchez L, Cuenca-Navarro N. [Vascular morphological and microdensity changes of corneal neovascularization induced by topical bevacizumab and sunitinib in an animal model]. Arch Soc Esp Oftalmol 2013; 88: 473-81. 
21. Csaky KG, Dugel PU, Pierce AJ, Fries MA, Kelly DS, Danis RP, Wurzelmann JI, $\mathrm{Xu} C F$, Hossain M, Trivedi T. Clinical evaluation of pazopanib eye drops versus ranibizumab intravitreal injections in subjects with neovascular age-related macular degeneration. Ophthalmology 2015; 122: 579-88.

22. Amparo F, Sadrai Z, Jin Y, Alfonso-Bartolozzi B, Wang H, Shikari H, Ciolino JB, Chodosh J, Jurkunas U, Schaumberg DA, Dana R. Safety and efficacy of the multitargeted receptor kinase inhibitor pazopanib in the treatment of corneal neovascularization. Investigative ophthalmology \& visual science 2013; 54: 537-44.

23. Campos-Mollo E, Perez-Santonja JJ, Lledo-Riquelme M, Ortega Pastor E, Alio JL. New corneal neovascularization model in rabbits for angiogenesis research. Ophthalmic Res 2011; 45: 135-41.

24. Darland DC, D'Amore PA. Cell-cell interactions in vascular development. Curr Top Dev Biol 2001; 52: 107-49.

25. Lindblom P, Gerhardt H, Liebner S, Abramsson A, Enge M, Hellstrom $M$, Backstrom G, Fredriksson S, Landegren U, Nystrom HC, Bergstrom G, Dejana E, Ostman A, Lindahl P, Betsholtz C. Endothelial PDGF-B retention is required for proper investment of pericytes in the microvessel wall. Genes Dev 2003; 17: $1835-40$.

26. Jain RK. Molecular regulation of vessel maturation. Nat Med 2003; 9: 685-93.

27. Erber $R$, Thurnher $A$, Katsen $A D$, Groth $G$, Kerger $H$, Hammes HP, Menger MD, Ullrich A, Vajkoczy P. Combined inhibition of VEGF and PDGF signaling enforces tumor vessel regression by interfering with pericyte-mediated endothelial cell survival mechanisms. FASEB J 2004; 18: 338-40.

28. Bergers G, Song S, Meyer-Morse N, Bergsland E, Hanahan D. Benefits of targeting both pericytes and endothelial cells in the tumor vasculature with kinase inhibitors. J Clin Invest 2003; 111: 1287-95.

29. Kang S, Roh CR, Cho WK, Park KC, Yang KJ, Choi HS, Kim SH, Roh YJ. Antiangiogenic effects of axitinib, an inhibitor of vascular endothelial growth factor receptor tyrosine kinase, on laser-induced choroidal neovascularization in mice. Curr Eye Res 2013; 38: 119-27. 
30. Giddabasappa A, Lalwani K, Norberg R, Gukasyan HJ, Paterson D, Schachar RA, Rittenhouse K, Klamerus K, Mosyak L, Eswaraka J. Axitinib inhibits retinal and choroidal neovascularization in in vitro and in vivo models. Experimental eye research 2016; 145: 373-9.

31. Cursiefen C, Hofmann-Rummelt C, Kuchle M, Schlotzer-Schrehardt U. Pericyte recruitment in human corneal angiogenesis: an ultrastructural study with clinicopathological correlation. Br J Ophthalmol 2003; 87: 101-6.

32. Reinmuth N, Liu W, Jung YD, Ahmad SA, Shaheen RM, Fan F, Bucana CD, McMahon G, Gallick GE, Ellis LM. Induction of VEGF in perivascular cells defines a potential paracrine mechanism for endothelial cell survival. FASEB J 2001; 15: 1239-41.

33. Bergers $G$, Song $S$. The role of pericytes in blood-vessel formation and maintenance. Neuro Oncol2005; 7: 452-64.

34. Chaoran Z, Zhirong L, Gezhi X. Combination of vascular endothelial growth factor receptor/platelet-derived growth factor receptor inhibition markedly improves the antiangiogenic efficacy for advanced stage mouse corneal neovascularization. Graefes Arch Clin Exp Ophthalmo/2011; 249: 1493-501.

35. Hos D, Bock F, Dietrich T, Onderka J, Kruse FE, Thierauch KH, Cursiefen C. Inflammatory corneal (lymph)angiogenesis is blocked by VEGFR-tyrosine kinase inhibitor ZK 261991, resulting in improved graft survival after corneal transplantation. Investigative ophthalmology \& visual science 2008; 49: 1836-42.

36. Rixe O, Bukowski RM, Michaelson MD, Wilding G, Hudes GR, Bolte O, Motzer RJ, Bycott P, Liau KF, Freddo J, Trask PC, Kim S, Rini BI. Axitinib treatment in patients with cytokine-refractory metastatic renal-cell cancer: a phase II study. Lancet Oncol 2007; 8: 975-84.

37. Cursiefen C, Masli S, Ng TF, Dana MR, Bornstein P, Lawler J, Streilein JW. Roles of thrombospondin-1 and -2 in regulating corneal and iris angiogenesis. Investigative ophthalmology \& visual science 2004; 45: 1117-24.

38. Enge M, Bjarnegard M, Gerhardt H, Gustafsson E, Kalen M, Asker N, Hammes HP, Shani M, Fassler R, Betsholtz C. Endothelium-specific platelet-derived 
growth factor-B ablation mimics diabetic retinopathy. EMBO J 2002; 21: 4307-16.

39. Ko BY, Kim YS, Baek SG, Lee GW, Kim JM, Jean WS, Lee NS, Kang J. Inhibition of corneal neovascularization by subconjunctival and topical bevacizumab and sunitinib in a rabbit model. Cornea 2013; 32: 689-95. 